\title{
Co-seismic strain-steps associated with the 2004 off the Kii peninsula earthquakes-Observed with Ishii-type borehole strainmeters and quartz-tube extensometers
}

\author{
Yasuhiro Asai ${ }^{1}$, Makoto Okubo ${ }^{1}$, Hiroshi Ishii ${ }^{1}$, Harumi Aoki ${ }^{1}$, Tsuneo Yamauchi ${ }^{2}$, Yuuichi Kitagawa ${ }^{3}$, and Naoji Koizumi ${ }^{3}$ \\ ${ }^{1}$ Tono Research Institute of Earthquake Science, Association for the Development of Earthquake Prediction, 1-63 Akeyo-cho Yamanouchi, \\ Mizunami, Gifu 509-6132, Japan \\ ${ }^{2}$ Nagoya University, Furou-cho Chikusa-ku Nagoya 464-8602, Japan \\ ${ }^{3}$ Geological Survey of Japan, National Institute of Advanced Industrial Science and Technology, \\ 1-1-1 Higashi, Tsukuba, Ibaraki 305-8567, Japan
}

(Received November 30, 2004; Revised March 25, 2005; Accepted March 28, 2005)

\begin{abstract}
The 2004 off the Kii peninsula earthquakes (Mj7.1 and Mj7.4) occurred at the Nankai trough, on 5 September 2004. Clear strain-steps associated with these earthquakes were observed with Ishii-type borehole strainmeters and quartz-tube extensometers in the Tokai and Kinki districts. We investigated the spatial and depth distribution of the observed principal strain changes and compared the observed strain-steps and theoretical calculations at all observatories. The following results were obtained: the observed strain-steps at all observatories are generally consistent with the polarities of the theoretical values, and the observed strain-step increases with depth at the same place. As for the Togari site, the following relationships are obtained: the strain-step and the tidal strains increase with depth and increasing of the modulus of elasticity, namely, hardness of rock. We consider that the geological structure around the observatory may cause a modification of the strain field.
\end{abstract}

Key words: The 2004 off the Kii peninsula earthquakes, strain-step, principal strain, Ishii-type borehole strainmeter, quartz-tube extensometer, modification of strain field.

\section{Introduction}

Strain-steps associated with large earthquakes have been reported during the last few decades. For example, Kasahara (1974) and Okada (1975) investigated the space distribution of the co-seismic strain-steps observed with extensometers which are widely distributed throughout Japan, and compared the co-seismic strain-steps with the theoretical values from a dislocation model of the earthquakes, showing many strain steps which agree with the polarity of the theoretical value and some strain steps which do not agree. They suggested the mechanical instability of the observation equipment, groundwater flow change, etc, as possible causes. However, the causes are inconclusive.

During the last 10 years, in the Tokai and Kinki districts of central Japan, several crustal movement observatories were built by the Tono Research Institute of Earthquake Science (TRIES) and Geological Survey of Japan (GSJ), and stable continuous observations have been performed with a 20 bit A/D resolution, far superior to that of the previous resolution. In the Tokai district, Nagoya University has been performing continuous crustal movement observations for the last 30 years. Under these circumstances, the 2004 off the Kii peninsula earthquakes (Mj7.1 foreshock and Mj7.4 main shock) occurred at the Nankai trough at 19:07 and 23:57 (JST), 5 September 2004, respectively (Fig. 1).

Copy right(c) The Society of Geomagnetism and Earth, Planetary and Space Sciences (SGEPSS); The Seismological Society of Japan; The Volcanological Society of Japan; The Geodetic Society of Japan; The Japanese Society for Planetary Sciences; TERRAPUB
Clear strain-steps associated with these earthquakes were observed at each observatory. In this study, we investigate the spatial and depth distribution of the observed strainsteps and compare the observed steps with the theoretical values from a dislocation model of the earthquakes, and attempt to clarify the differences of the strain field.

\section{Observation}

We analyzed the crustal strain data of the observatories shown in Fig. 1 and Table 1. The Byobu-san borehole observatory (BYB) is the deepest multi-component continuous monitoring of crustal activities in the world (Ishii et al., 2003). The Togari borehole observatory consists of two boreholes with depths of $350 \mathrm{~m}$ (TGR350) and $165 \mathrm{~m}$ (TGR165). These two boreholes were drilled about $3 \mathrm{~m}$ apart. The instruments were installed in the granite bedrock all three borehole observatories, which belong to TRIES. At the Mizunami vault-type observatory (NAMZ) is located in the Tertiary sedimentary rocks. The Asahi (NAAS), the Inabu (NAIB) and the Toyohashi (NATY) are vault-type observatories. NAAS and NAIB are located in the granite. NATY is located in the pre-Tertiary sedimentary rocks. These four vault-type observatories belong to Nagoya University. At the Toyohashi borehole observatory (TYH1) and the Ohara borehole observatory (OHR), belonging to GSJ, the instruments were installed in the pre-Tertiary sedimentary rocks and pre-Tertiary volcanic rocks, respectively. At these borehole and vault-type observatories, crustal strains were measured by Ishii-type borehole strainmeters (Ishii et 


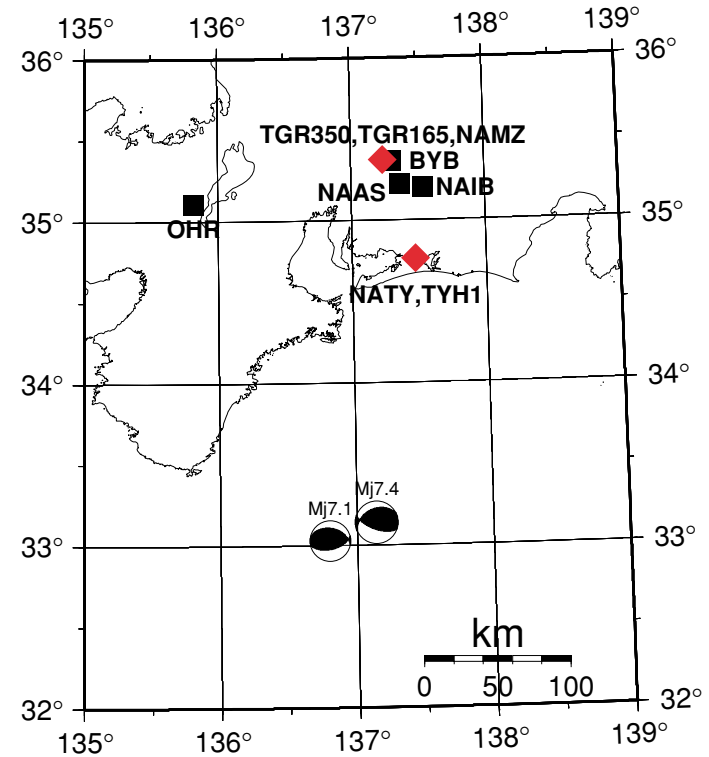

Fig. 1. Location map of the epicenters (the locations of the earthquakes and their CMT solutions by the Japan Meteorological Agency, 2004). Black squares and red diamonds indicate the observatories and the three-dimensional array observation system of crustal movements, respectively.

al., 2002) and quartz-tube extensometers, respectively. The sampling interval of the strain data at TGR350, TGR165 and NAMZ is $1 \mathrm{~Hz}, 20 \mathrm{~Hz}$ at BYB, 1 min at NAAS, NAIB and NATY, and 2 min at TYH1 and OHR.

TGR350 and TGR165 are located about $100 \mathrm{~m}$ southwest of NAMZ. TYH1 is located about $100 \mathrm{~m}$ south of NATY. Using the borehole observatory and at close proximity to the vault-type, we constructed a "three dimensional array observation system of crustal movements" at Togari (TGR350, TGR165 and NAMZ) and Toyohashi (TYH1 and NATY). We observed the crustal strains at different depths
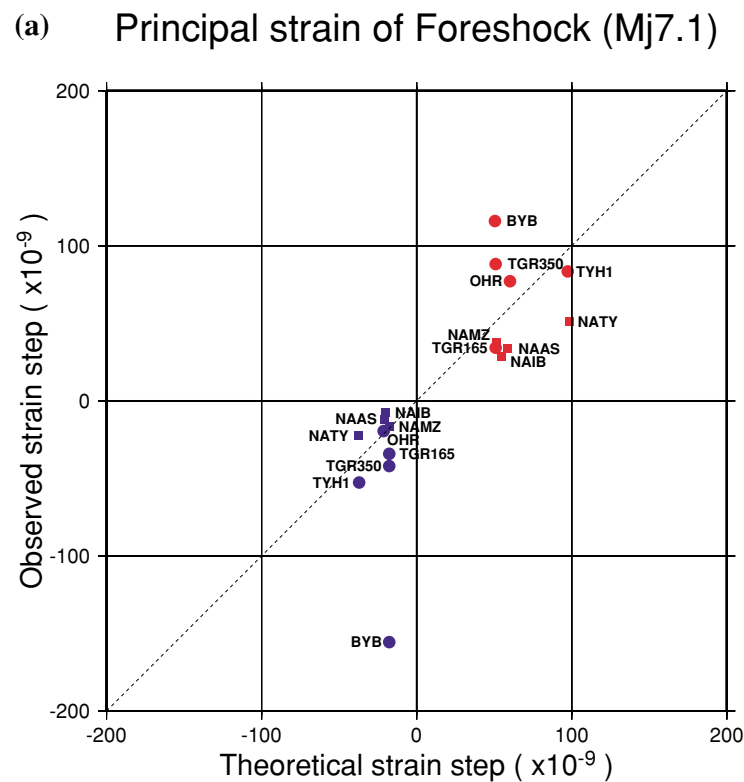

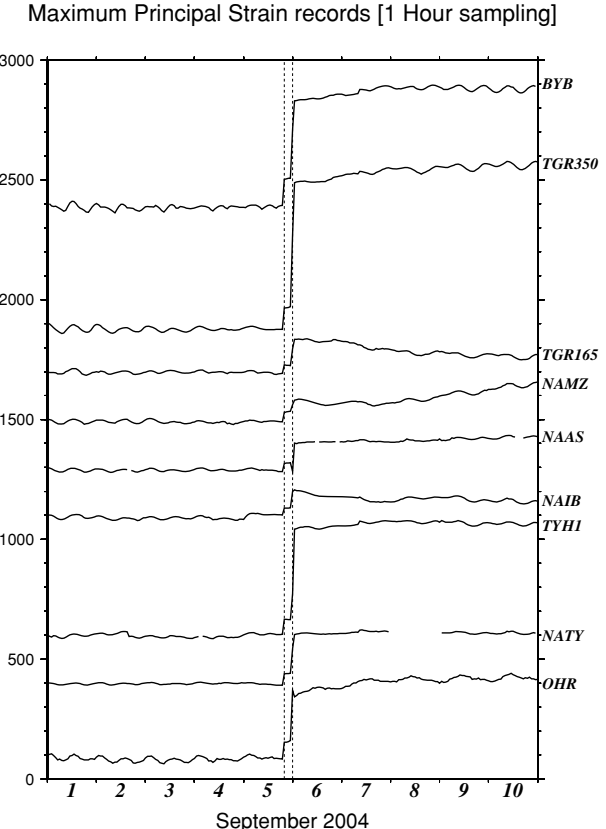

Fig. 2. Hourly maximum principal strain of all observatories. A vertical dashed line indicates the origin time of the foreshock and the main shock, respectively.

in the same places using these array systems (Fig. 1 and Table 1).

\section{Analysis}

To investigate the strain field changes, namely the principal strain changes associated with the foreshock and the main shock at each observatory, we analyzed the strain data using the following procedures [1]. To standardize the various sampling interval data, a sampling interval of $1 \mathrm{~h}$ was selected. The data for a month in September 2004 were smoothed by applying a low-pass filter (moving average

\section{(b) Principal strain of Main shock (Mj7.4)}

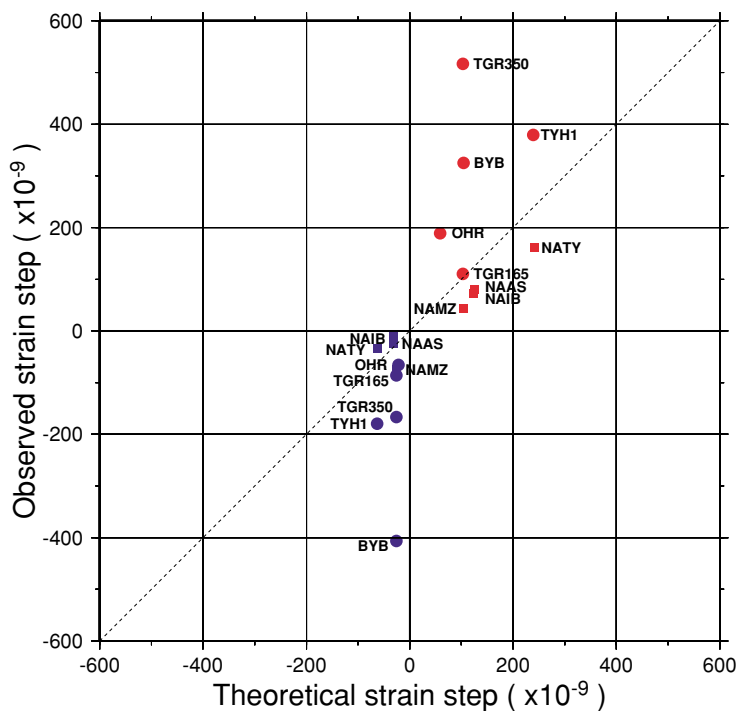

Fig. 3. Comparison of the observed strain-steps of maximum (red marks) and minimum (blue marks) principal strain for the foreshock with the theoretical values (a), and for the main shock (b). The circles and the squares indicate the borehole strainmeter and the quartz-tube extensometer, respectively. 
Table 1. List of the observatories.

\begin{tabular}{|c|c|c|c|c|c|c|c|c|c|c|c|c|}
\hline Station & $\begin{array}{l}\text { Latitude } \\
\text { (deg) }\end{array}$ & $\begin{array}{c}\text { Longitude } \\
\text { (deg) }\end{array}$ & $\begin{array}{l}\text { Altitude } \\
(\mathrm{m})\end{array}$ & $\begin{array}{l}\text { Depth } \\
\text { (m) }\end{array}$ & Geology & $\begin{array}{l}\text { Density } \\
\text { (g/cm3) }\end{array}$ & $\begin{array}{c}\mathrm{Vp} \\
(\mathrm{km} / \mathrm{s})\end{array}$ & $\begin{array}{c}\mathrm{Vs} \\
(\mathrm{km} / \mathrm{s})\end{array}$ & $\begin{array}{c}\text { Shear modulus } \\
\text { (GPa) }\end{array}$ & $\begin{array}{l}\text { Bulk modulus } \\
(\mathrm{GPa})\end{array}$ & $\begin{array}{l}\text { Young modulus } \\
(\mathrm{GPa})\end{array}$ & Poisson ratio \\
\hline BYB & 35.3643 & 137.3039 & 333 & 1020 & G & 2.62 & 4.72 & 2.71 & 19.24 & 32.71 & 48.26 & 0.25 \\
\hline \multicolumn{13}{|l|}{ Togari site } \\
\hline TGR350 & 35.3745 & 137.2378 & 190 & 350 & G & 2.59 & 5.18 & 2.57 & 17.11 & 46.69 & 45.73 & 0.34 \\
\hline TGR165 & 35.3745 & 137.2378 & 190 & 165 & G & 2.54 & 4.23 & 1.64 & 6.83 & 36.34 & 19.29 & 0.41 \\
\hline NAMZ & 35.3755 & 137.2388 & 195 & 20 & $\mathrm{~T}$ & 1.83 & 2.08 & 1.00 & 1.83 & 5.48 & 4.93 & 0.35 \\
\hline NAAS & 35.2249 & 137.3620 & 200 & 50 & G & & & & & & & \\
\hline NAIB & 35.2015 & 137.5337 & 700 & 50 & G & & & & & & & \\
\hline \multicolumn{13}{|l|}{ Toyohashi site } \\
\hline TYH1 & 34.7643 & 137.4667 & 77 & 250 & pT & 2.69 & 4.58 & 2.53 & 17.33 & 33.69 & 44.39 & 0.28 \\
\hline NATY & 34.7652 & 137.4667 & 76 & 50 & pT & & & & & & & \\
\hline OHR & 35.1105 & 135.8193 & 217 & 278 & G & & & & & & & \\
\hline
\end{tabular}

G: Granite, T: Tertiary sedimentary rocks, pT: pre-Tertiary sedimentary rocks.

Table 2. Comparison of the observed strain-steps (Obs) and theoretical calculations (M-1 to M-4) for the foreshock (upper table), and the main shock (lower table). $\alpha$ is a modification coefficient. Unit of observed strain-step (Obs) and theoretical calculations are nano-strain. Unit of the direction of the maximum principal strain is degrees; clockwise from the north are positive.

\begin{tabular}{|c|c|c|c|c|c|c|c|c|c|c|c|c|c|c|c|c|c|}
\hline \multirow{2}{*}{$\begin{array}{c}\text { Foreshock } \\
\text { Mj7.1 }\end{array}$} & \multicolumn{6}{|c|}{ Maximum Principal strain } & \multicolumn{6}{|c|}{ Minimum Principal strain } & \multicolumn{5}{|c|}{ Direction of Maximum Principal strain } \\
\hline & Obs & M-1 & $\mathrm{M}-2$ & M-3 & M-4 & $\alpha$ & Obs & M-1 & M-2 & $\mathrm{M}-3$ & M-4 & $\alpha$ & Obs & M-1 & $\mathrm{M}-2$ & M-3 & M-4 \\
\hline BYB & 116.0 & 52.1 & 50.6 & 53.3 & 74.9 & 2.3 & -155.5 & -18.4 & -17.5 & -17.8 & -25.6 & 8.9 & 15.5 & 14.4 & 13.4 & 13.2 & 12.6 \\
\hline \multicolumn{18}{|l|}{ Togari site } \\
\hline TGR350 & 88.3 & 52.9 & 51.1 & 53.8 & 75.7 & 1.7 & -42.1 & -18.4 & -17.6 & -17.9 & -25.6 & 2.4 & 21.7 & 12.8 & 11.7 & 11.5 & 10.9 \\
\hline TGR165 & 34.4 & 52.9 & 51.1 & 53.8 & 75.7 & 0.7 & -34.1 & -18.4 & -17.5 & -17.9 & -25.6 & 1.9 & 6.1 & 12.8 & 11.7 & 11.5 & 10.9 \\
\hline NAMZ & 37.9 & 53.4 & 51.5 & 54.2 & 76.3 & 0.7 & -16.6 & -18.5 & -17.6 & -17.9 & -25.7 & 0.9 & 28.0 & 12.1 & 11.1 & 10.9 & 10.3 \\
\hline NAAS & 33.5 & 59.8 & 58.4 & 62.0 & 87.2 & 0.6 & -11.7 & -21.5 & -20.5 & -21.0 & -30.2 & 0.6 & 10.3 & 16.8 & 15.7 & 15.6 & 14.9 \\
\hline NAIB & 28.6 & 55.6 & 55.0 & 58.5 & 82.3 & 0.5 & -7.8 & -20.8 & -19.9 & -20.3 & -29.3 & 0.4 & 17.5 & 21.2 & 20.1 & 20.1 & 19.4 \\
\hline \multicolumn{18}{|l|}{ Toyohashi site } \\
\hline TYH1 & 83.6 & 98.1 & 97.7 & 106.5 & 151.8 & 0.9 & -52.6 & -38.5 & -37.0 & -38.7 & -56.5 & 1.4 & 30.3 & 24.5 & 23.3 & 23.4 & 22.3 \\
\hline NATY & 50.9 & 99.1 & 98.6 & 107.6 & 153.3 & 0.5 & -22.5 & -38.8 & -37.3 & -39.0 & -56.9 & 0.6 & 19.5 & 24.3 & 23.1 & 23.2 & 22.0 \\
\hline OHR & 77.3 & 68.4 & 60.3 & 61.4 & 89.4 & 1.3 & -19.5 & -23.0 & -21.1 & -21.5 & -30.5 & 0.9 & -39.9 & -23.0 & -24.2 & -25.1 & -25.1 \\
\hline Main shock & \multicolumn{6}{|c|}{ Maximum Principal strain } & \multicolumn{6}{|c|}{ Minimum Principal strain } & \multicolumn{5}{|c|}{ Direction of Maximum Principal strain } \\
\hline $\mathrm{Mj} 7.4$ & Obs & M-1 & M-2 & M-3 & M-4 & $\alpha$ & Obs & M-1 & M-2 & M-3 & M-4 & $\alpha$ & Obs & M-1 & M-2 & M-3 & M-4 \\
\hline BYB & 325.1 & 96.3 & 104.3 & 100.5 & 79.6 & 3.1 & -406.5 & -27.6 & -25.8 & -25.7 & -20.1 & 15.8 & 13.3 & 3.3 & 4.4 & 5.2 & 2.5 \\
\hline \multicolumn{18}{|l|}{ Togari site } \\
\hline TGR350 & 516.9 & 95.1 & 103.3 & 99.8 & 78.4 & 5.0 & -166.6 & -27.1 & -25.5 & -25.3 & -19.7 & 6.5 & 33.5 & 1.4 & 2.5 & 3.3 & 0.4 \\
\hline TGR165 & 110.5 & 95.1 & 103.3 & 99.8 & 78.4 & 1.1 & -86.2 & -27.1 & -25.4 & -25.3 & -19.7 & 3.4 & 4.3 & 1.4 & 2.5 & 3.3 & 0.4 \\
\hline NAMZ & 42.5 & 94.9 & 103.3 & 99.8 & 78.2 & 0.4 & -75.0 & -27.0 & -25.4 & -25.3 & -19.6 & 3.0 & 39.4 & 0.7 & 1.7 & 2.5 & -0.4 \\
\hline NAAS & 81.2 & 115.5 & 125.0 & 120.1 & 96.9 & 0.6 & -24.2 & -33.3 & -31.0 & -30.7 & -24.6 & 0.8 & 3.0 & 5.5 & 6.8 & 7.7 & 4.9 \\
\hline NAIB & 72.2 & 115.9 & 123.3 & 117.7 & 97.4 & 0.6 & -7.1 & -33.6 & -30.9 & -30.5 & -24.8 & 0.2 & 15.6 & 10.7 & 12.3 & 13.2 & 10.6 \\
\hline \multicolumn{18}{|l|}{ Toyohashi site } \\
\hline TYH1 & 379.1 & 220.4 & 239.5 & 226.1 & 194.5 & 1.6 & -179.5 & -67.8 & -62.8 & -61.2 & -53.4 & 2.9 & 28.6 & 12.0 & 14.2 & 15.4 & 12.4 \\
\hline NATY & 160.9 & 221.9 & 241.4 & 228.0 & 196.0 & 0.7 & -34.0 & -68.2 & -63.1 & -61.5 & -53.7 & 0.5 & 10.4 & 11.7 & 13.9 & 15.2 & 12.1 \\
\hline OHR & 189.0 & 51.4 & 59.0 & 59.0 & 34.5 & 3.2 & -65.3 & -22.9 & -21.8 & -22.5 & -18.2 & 3.0 & -59.1 & -44.8 & -42.9 & -42.3 & -55.5 \\
\hline
\end{tabular}

with cut-off frequency of $30 \mathrm{~min}$; Asai et al., 2001) before extracting hourly data from the original data [2]. Using the tidal analysis program BAYTAP-G (Tamura et al., 1991), we calculated the solid Earth tide component and the atmospheric pressure response of each data; they were then removed from the data and the residual component was obtained [3]. Assuming plane strain, the principal strain was calculated from the residuals of the three independent directions and the size of step and the direction of maximum principal strain associated with the foreshock and the main shock were calculated after subtracting a liner trend fit to $115 \mathrm{~h}$ of data preceding the foreshock so as to minimize the strain variation before the earthquake (Obs in Table 2). Figure 2 shows the hourly maximum principal strain of all observatories from 1 to 10 September as an example.

The theoretical principal strain associated with the foreshock and the main shock at each observatory were calculated by the four fault models of the Geographical Survey Institute (GSI) (M-1 to M-4 in Table 3; Geographical Survey Institute, 2004) which are inferred from the co-seismic horizontal movements by GEONET (GPS Earth Observation Network; Miyazaki et al., 1997). The Earth's crust was approximated as an isotropic homogeneous semiinfinite elastic medium. The altitudes of vault-type obser- vatories were set at sea-level, and the installation depths of borehole equipment were set below sea-level. Using these model parameters with the MICAP-G program (Naito and Yoshikawa, 1999) based on Okada (1992), we calculated the principal strain and direction of the maximum principal strain at each observatory (M-1 to M-4 in Table 2).

\section{Discussion and Conclusion}

As space is limited, we have only focused on the differences of the amplitude of principal strain. The theoretical values of the principal strains in each observatory are almost the same, while the values from GSI's model M4 are slightly different compared to the other models (see Table 2). As for GSI's models M-2 and M-3, these models are consistent with the aftershock distribution and the fault model on the basis of the displacement field obtained by a campaign survey of GPS in the southern Kii peninsula (Hashimoto et al., 2005). Therefore, comparison of the theoretical values, which were calculated from GSI's model M-2 of the foreshock, and those observed are shown in Fig. 3(a) as an example. Similar plots of observed strainsteps for the main shock are shown in Fig. 3(b). The theoretical values at different depths at the Togari site (TGR165, TGR350 and NAMZ) and the Toyohashi site (TYH1 and 
The modulus of elasticity profiles

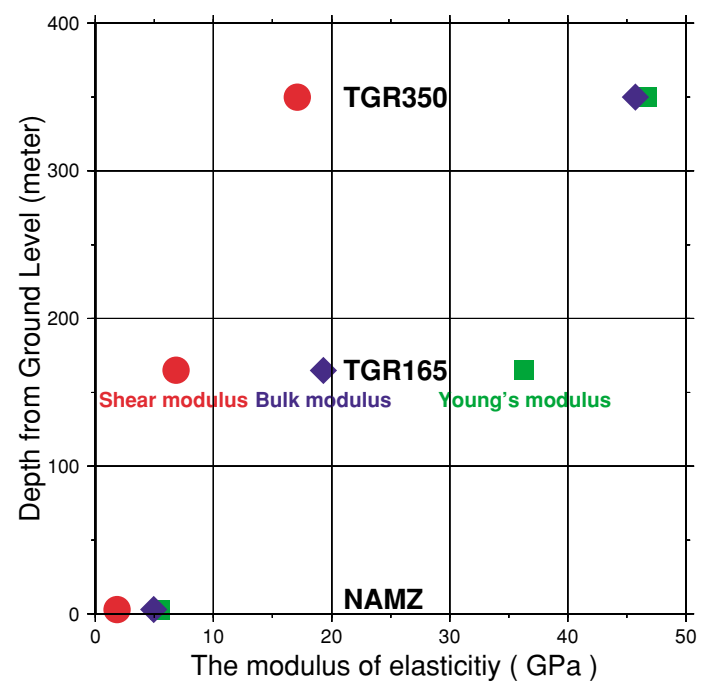

Fig. 4. The modulus of elasticity at different depths at the Togari site.

(a) Principal strain - Young's modulus

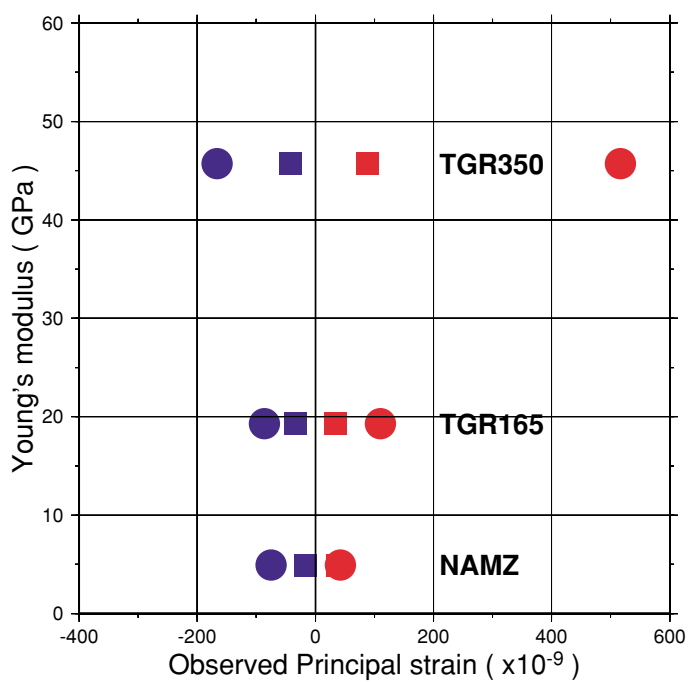

(b) Principal strain - Bulk modulus

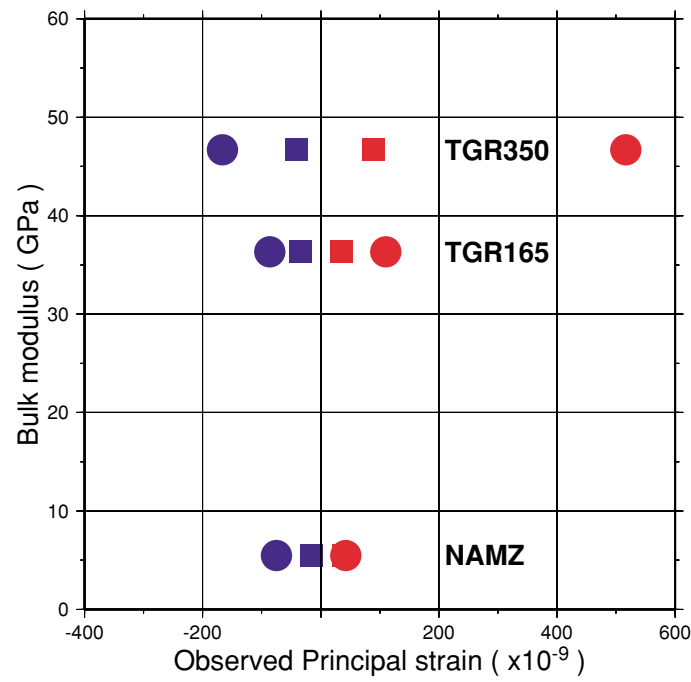

(c) Principal strain - Shear modulus

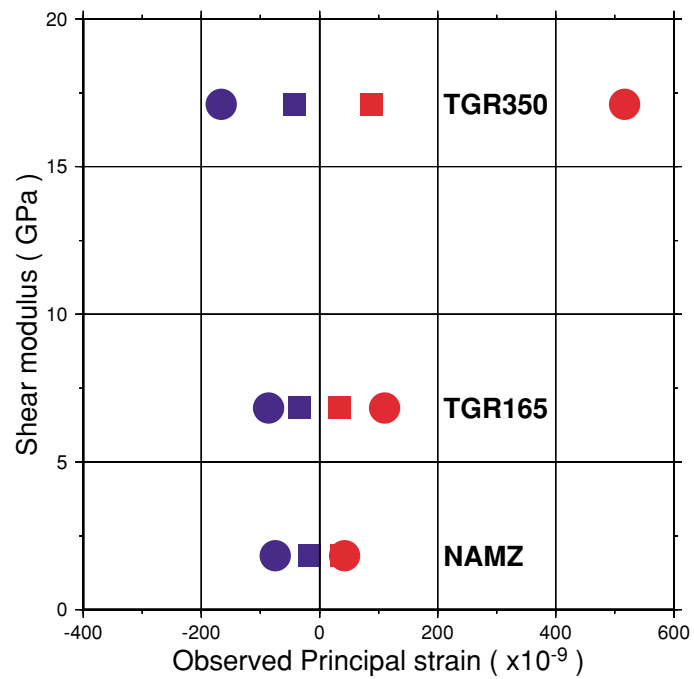

(d) Principal strain - Poisson's ratio

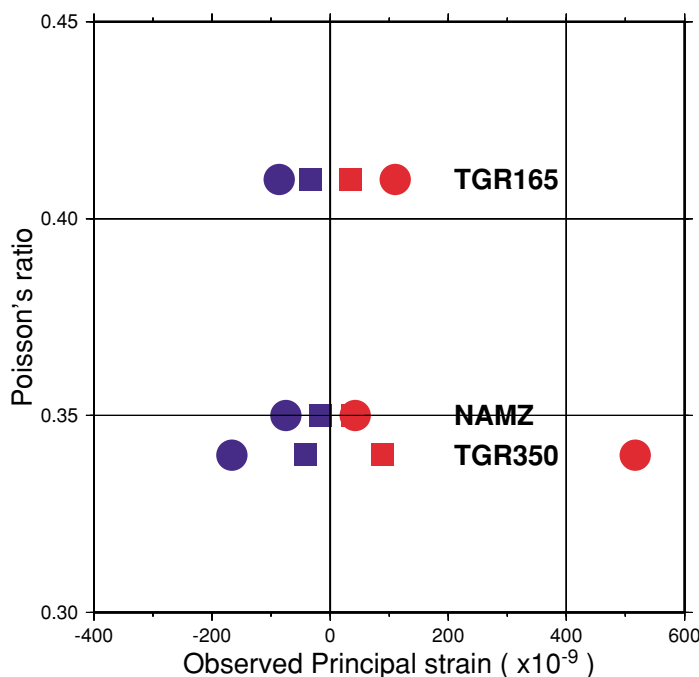

Fig. 5. Comparison of the observed strain-step of maximum (red marks) and minimum (blue marks) principal strain for the foreshock (squares) and the main shock (circles) with Young's modulus (a), bulk modulus (b), shear modulus (c), and Poisson's ratio (d), respectively. 
Table 3. GSI's (2004) fault model for the foreshock (upper table) and the main shock (lower table).

\begin{tabular}{|c|c|c|c|c|c|c|c|c|c|c|}
\hline $\begin{array}{c}\text { Foreshock } \\
\text { Mj7.1 }\end{array}$ & $\begin{array}{l}\text { Latitude } \\
\text { (deg) }\end{array}$ & $\begin{array}{c}\text { Longitude } \\
\text { (deg) }\end{array}$ & $\begin{array}{l}\text { Length } \\
(\mathrm{km})\end{array}$ & $\begin{array}{l}\text { Width } \\
(\mathrm{km})\end{array}$ & $\begin{array}{l}\text { Depth } \\
(\mathrm{km})\end{array}$ & $\begin{array}{l}\text { Strike } \\
(\mathrm{deg})\end{array}$ & $\begin{array}{c}\text { Dip } \\
\text { (deg) }\end{array}$ & $\begin{array}{l}\text { Rake } \\
(\text { deg })\end{array}$ & $\begin{array}{l}\text { Slip } \\
(\mathrm{m})\end{array}$ & $\mathrm{Mw}$ \\
\hline M-1 & 32.97 & 136.95 & 30.1 & 19.8 & 9.3 & 267 & 47 & 98 & 4.27 & 7.2 \\
\hline M-2 & 32.97 & 136.95 & 30.0 & 19.7 & 11.3 & 267 & 47 & 92 & 4.00 & 7.2 \\
\hline M-3 & 32.97 & 136.94 & 30.1 & 19.3 & 12 & 280 & 41 & 108 & 3.83 & 7.1 \\
\hline M-4 & 33.03 & 136.67 & 30.1 & 19.9 & 11.2 & 71 & 58 & 76 & 5.59 & 7.3 \\
\hline $\begin{array}{c}\text { Main shock } \\
\text { Mj7.4 }\end{array}$ & $\begin{array}{c}\text { Latitude } \\
\text { (deg) }\end{array}$ & $\begin{array}{c}\text { Longitude } \\
\text { (deg) }\end{array}$ & $\begin{array}{l}\text { Length } \\
(\mathrm{km})\end{array}$ & $\begin{array}{l}\text { Width } \\
(\mathrm{km})\end{array}$ & $\begin{array}{c}\text { Depth } \\
(\mathrm{km})\end{array}$ & $\begin{array}{l}\text { Strike } \\
(\mathrm{deg})\end{array}$ & $\begin{array}{c}\text { Dip } \\
\text { (deg) }\end{array}$ & $\begin{array}{l}\text { Rake } \\
(\text { deg })\end{array}$ & $\begin{array}{l}\text { Slip } \\
(\mathrm{m})\end{array}$ & $\mathrm{Mw}$ \\
\hline M-1 & 33.18 & 137.25 & 34.4 & 21.5 & 15.3 & 245 & 62 & 50 & 5.1 & 7.3 \\
\hline M-2 & {$\left[\begin{array}{l}33.11 \\
33.10\end{array}\right.$} & $\begin{array}{l}137.29 \\
137\end{array}$ & 34.8 & 18.1 & $\begin{array}{c}16.9 \\
5.8\end{array}$ & 245 & $\begin{array}{l}54 \\
85\end{array}$ & 62 & $\begin{array}{l}3.44 \\
2.84\end{array}$ & 7.3 \\
\hline \multirow{2}{*}{ M-3 } & 33.11 & 137.32 & 38 & 25.1 & 17.1 & 265 & 52 & 88 & 2.28 & \multirow{2}{*}{7.3} \\
\hline & L33.16 & 137.18 & 32.5 & 15.4 & 7.5 & 323 & 90 & 150 & لـ3.39 & \\
\hline M-4 & 33.41 & 136.67 & 30.1 & 19.9 & 11.2 & 71 & 58 & 76 & 5.59 & 7.2 \\
\hline
\end{tabular}

Table 4. Tidal analysis results of maximum and minimum principal strains concerning the Togari site and Toyohashi site, for one month in September 2004. We focused on M2 and O1 constituents because the disturbance of meteorological phenomena does not have much affect much in these constituents. The unit of Amplitude (Amp.) is nano-strain. Phase is the phase shift with respect to local potential; positive value indicates phase lead. RMSE is the root mean square error.

\begin{tabular}{|c|c|c|c|c|c|c|c|c|c|c|c|c|c|c|c|c|}
\hline & \multicolumn{8}{|c|}{ Maximum Principal strain } & \multicolumn{8}{|c|}{ Minimum Principal strain } \\
\hline & \multicolumn{4}{|c|}{ M2 } & \multicolumn{4}{|c|}{$\mathrm{O} 1$} & \multicolumn{4}{|c|}{ M2 } & \multicolumn{4}{|c|}{$\mathrm{O} 1$} \\
\hline & Amp. & (RMSE) & Phase & (RMSE) & Amp. & (RMSE) & Phase & (RMSE) & Amp. & (RMSE) & Phase & (RMSE) & Amp. & (RMSE) & Phase & (RMSE) \\
\hline \multicolumn{17}{|l|}{ Togari site } \\
\hline TGR350 & 11.4 & 0.2 & -16.3 & 1.0 & 4.6 & 0.7 & 43.9 & 9.0 & 11.0 & 0.3 & 15.6 & 1.3 & 9.5 & 0.8 & -31.1 & 4.6 \\
\hline TGR165 & 6.9 & 0.4 & -23.0 & 2.9 & 5.4 & 1.3 & 27.4 & 13.3 & 5.1 & 0.4 & 30.7 & 4.0 & 4.2 & 1.2 & -46.2 & 17.0 \\
\hline NAMZ & 6.8 & 0.1 & -21.2 & 1.1 & 5.0 & 0.4 & 20.7 & 5.1 & 5.5 & 0.1 & 8.3 & 1.2 & 3.7 & 0.4 & 26.8 & 5.9 \\
\hline \multicolumn{17}{|c|}{ Toyohashi site } \\
\hline TYH1 & 4.7 & 0.5 & -15.1 & 6.4 & 2.5 & 0.5 & -12.3 & 11.8 & 4.1 & 0.6 & 8.7 & 7.8 & 2.3 & 0.5 & 2.7 & 13.4 \\
\hline NATY & 4.3 & 0.1 & -35.0 & 1.4 & 1.6 & 0.4 & -10.0 & 13.0 & 2.4 & 0.1 & 9.5 & 2.0 & 3.1 & 0.3 & -10.1 & 5.4 \\
\hline
\end{tabular}

NATY) agreed in the nano-strain order (see Table 2). This shows that in these regions, which are more than $180 \mathrm{~km}$ from the hypocenter, there is no difference in the depth for the principal strain changes required in the isotropic homogeneous semi-infinite elastic medium model.

The observed strain-steps for the foreshock and the main shock at all observatories are generally consistent with the calculated polarities (Table 2, Figs. 3(a) and 3(b)). These agreements are surprising when compared to earlier reports that some observed strain-steps do not agree with the polarity of the calculated values (e.g. Kasahara, 1974; Okada, 1975), although they were directly compared to the strainsteps of each component. For the NAMZ, NAAS, NAIB, and NATY in the vault-type observatories, a device that suppresses the oscillations of extensometers during earthquakes (Yamauchi et al., 1975) appears to be a major factor in obtaining stable and sensible directional data.

At the Togari site (TGR350, TGR165 and NAMZ) and the Toyohashi site (TYH1 and NATY), there are clear differences in the observed strain-steps at different depths for the foreshock and the main shock. To make these differences clear, we obtained the modification coefficients $\alpha(\alpha>0)$ which are expressed as follows:

$$
\alpha=\varepsilon(\text { obs }) / \varepsilon(\text { theo })
$$

where $\varepsilon$ (obs) is the observed strain and $\varepsilon$ (theo) is the theoretical strain which is calculated from the model. The coefficients $\alpha$ for each observatory using GSI's model M-2 are shown in Table 2. At these sites, the coefficients $\alpha$ for the borehole observatory are larger than those for the vault-type (Table 2, Figs. 3(a) and 3(b)). Let us consider the coefficients $\alpha$ from the differences in the geological environments at these observatories. As mentioned in Section 2, TGR350 and TGR165 are located at different depths in granite bedrock. NAMZ is located in Tertiary sedimentary rocks. TYH1 and NATY are located at different depths in pre-Tertiary sedimentary rocks consisting of inclined layers of sandstone, chert and shale. Thus, we investigated the relation between the observed strain-steps and the geological environments using the physical properties of the rocks at each depth at the Togari site. As for the Toyohashi site, no investigation has been carried out, because we have no definite information on the physical properties of the rocks in NATY. The bulk modulus, the shear modulus, Young's modulus and Poisson's ratio at each depth were obtained from the $P$-wave and $S$-wave velocity and the density of rock at each depth, which were obtained from well loggings or examination of drilling core samples. Figure 4 shows the modulus of elasticity for each depth at the Togari site, and the modulus of elasticity increases with the depth. Figure 5(a) shows that the observed strain-step increases with Young's modulus. A similar plot for the bulk modulus, and shear modulus is shown in Figs. 5(b) and 5(c), respectively, excluding Poisson's ratio (Fig. 5(e)). Similar tendencies are observed in the tidal amplitudes, which obtained the tidal analysis of principal strain for a month in September 2004 (see Table 4 and Asai et al., 2001). At the Togari site, the coefficients $\alpha$ increases with depth and an increasing of the modulus of elasticity, namely, hardness of rock. This is strange because generally the strain in the rock decreases with the hardness.

As for geological structures, between TGR350, TGR165 
and NAMZ, there exists a sub-vertical fault with a NNW strike which was recognized geologically (JNC, 2003). TGR165 is located near the boundary between the Tertiary layers and granite bedrock with a depth of about 100 $\mathrm{m}$, where there are many cracks. There are also several confined aquifers at a depth of 200-360 $\mathrm{m}$ in the granite bedrock near the installation depth for TGR350 and TGR165, consisting of a joint system or cracks (JNC, 2003). We consider that these differences of the geological structure around the observatory, namely the heterogeneity of rocks, may cause a modification of the strain field. A detailed investigation of the modification is the subject for future study.

Acknowledgments. We would like to thank Y. Okada and the anonymous referee for improving the manuscript. We also wish to thank Takeyasu Yamamoto of the Meteorological Research Institute, JMA for his advice on the MICAP-G program.

\section{References}

Asai, Y., H. Aoki, T. Tanaka, Y. Kitagawa, and S. Azuma, Comparison of tidal changes of ground strain and groundwater level observed at clustered boreholes in the Tono region, central Japan, J. Geod. Soc. Japan, 47, 134-140, 2001.

Geographical Survey Institute, Fault models of the Off Kii-Peninsula Earthquakes, reported at the 161st meeting of the Coordinating Committee for Earthquake Prediction (CCEP), 2004 (in Japanese).

Hashimoto, M., K. Onoue, F. Ohya, Y. Hoso, K. Segawa, K. Sato, and Y. Fujita, Crustal deformations in Kii peninsula associated with the SE off the Kii peninsula earthquake sequence of September 5, 2004 derived from dense GPS observations, Earth Planets Space, 57, 185-190, 2005.

Ishii, H., T. Yamauchi, S. Matsumoto, Y. Hirata, and S. Nakao, Development of multi-component borehole instrument for earthquake prediction study: Some observed examples of precursory and co-seismic phenomena relating to earthquake swarms and application of the instrument for rock mechanics in Seismogenic process monitoring, edited by H. Ogasawara, T. Yanagidani and M. Ando, pp. 365-377, A. A BALKEMA
PUBL., 2002.

Ishii, H., T. Yamauchi, Y. Asai, M. Ohkubo, S. Matsumoto, and H. Aoki, Continuous multi-component monitoring of crustal activities by a newly developed instrument installed in a $1200 \mathrm{~m}$ depth borehole-The deepest multiple observation in the world consisting of stress, strain, tilt, seismic waves, geomagnetism, temperature, paper presented at IUGG XXIII General Assembly, Int. Union of Geod. and Geophys., Sapporo, JAPAN, 2003.

Japan Meteorological Agency, CMT solution, http://www.seisvol.kishou. go.jp/eq/mech/outer/cmt/event/0409051907_.html, 2004 (in Japanese).

Japan Meteorological Agency, CMT solution, http://www.seisvol.kishou. go.jp/eq/mech/outer/cmt/event/0409052357_.html, 2004 (in Japanese).

JNC, Annual report of research and development on HLW geological disposal in 2002, JNC Tech Rep., JNC TN1400 2003-004, 2003 (in Japanese).

Kasahara, M., Spatial distribution of strain-steps associated with the earthquake off the Nemuro peninsula, June 17, 1973, Research on June 17, 1973 Off Nemuro peninsula earthquake, pp. 36-62, 1974 (in Japanese with English abstract).

Miyazaki, S., T. Saito, M. Sasaki, Y. Hatanaka, and Y. Iimura, Expansion of GSI's nationwide GPS array, Bull. Geogr. Surv. Inst., 43, 23-34, 1997.

Naito, H. and S. Yoshikawa, A program to assist crustal deformation analysis, Zisin 2 (J. Seismol. Soc. Japan), 52, 101-103, 1999 (in Japanese with English abstract).

Okada, Y., Strain- and tilt-steps associated with the two earthquakes, which occurred in the east off Hachijojima, Japan, on February 29 and December 4, 1972, Zisin 2 (J. Seismol. Soc. Japan), 28, 387-413, 1975 (in Japanese with English abstract).

Okada, Y., Internal deformation due to shear and tensile faults in a halfspace, Bull. Seism. Soc. Am., 82, 1018-1040, 1992.

Tamura, Y., T. Sato, M. Ooe, and M. Ishiguro, A procedure for tidal analysis with a Bayesian information criterion, Geophys. J. Int., 104, 507-516, 1991.

Yamauchi, T., M. Yamada, and H. Aoki, Detection of strain step associated with earthquake, Zisin 2 (J. Seismol. Soc. Japan), 28, 51-59, 1975 (in Japanese with English abstract).

Y. Asai (e-mail: asai@tries.jp), M. Okubo, H. Ishii, H. Aoki, T. Yamauchi, Y. Kitagawa, and N. Koizumi 